\title{
Pelvic floor re-education reduced incontinence at 1 year after radical prostatectomy
}

\author{
Van Kampen M, De Weerdt W, Van Poppel H, et al. Effect of pelvic-floor re-education on duration and degree of \\ incontinence after radical prostatectomy: a randomised controlled trial. Lancet 2000 Jan 8;355:98-102.
}

\section{QUESTION: In patients with prostate cancer, does pelvic floor re-education (PFR) reduce the duration and degree of urinary incontinence after radical prostatectomy?}

\section{Design}

Randomised (unclear allocation concealment*), blinded (patients and outcome assessors),* controlled trial with follow up to 1 year.

\section{Setting \\ A university hospital in Leuven, Belgium.}

\section{Patients}

102 men (mean age 65 y) who had radical retropubic prostatectomy (maintaining pelvic floor structures) for clinically localised prostate cancer, were incontinent 15 days after surgery (after catheter removal), and could regularly attend hospital appointments. Follow up was $96 \%$.

\section{Intervention}

Patient allocation was stratified by previous transurethral resection of the prostate and urine loss 1 day after catheter removal. 50 men were allocated to a PFR programme, which consisted of individual treatment in an outpatient clinic once a week for as long as incontinence persisted, up to 1 year. The training programme included education about the anatomy and function of the bladder and pelvic floor, active pelvic floor muscle exercises, and biofeedback. After patients learnt to do the exercises, they were instructed to do 90 contractions per day at home in standing, sitting, or supine positions and to integrate the contractions into their daily activities. 52 men were allocated to a placebo programme, which included information about the origin of their incontinence and placebo electrotherapy that was applied to the abdomen and thighs but that could not affect pelvic floor function.

\section{Main outcome measures}

Incontinence rate at 3 months. Continence was defined as a loss of $\leqslant 2 \mathrm{~g}$ of urine on both the 24 hour and 1 hour pad test (ie, difference in wet and dry pad weight). Secondary outcomes included incontinence at 1 year, duration of incontinence, and degree of incontinence (average urine loss/24 h).

\section{Main results}

On average, men in the PFR group attended 8 outpatient sessions, and men in the placebo group attended 16. Fewer men in the PFR group were still incontinent at 3 months and at 1 year than were men in the placebo group (table). At 3 months, the duration of incontinence was shorter in the PFR group $(\log$ rank test $\mathrm{p}<0.001)$. At 1 year, the degree of incontinence was lower for the PFR group (Wald test $\mathrm{p}=0.001$ ).

\section{Conclusion}

Pelvic floor re-education, which included biofeedback and regular exercises, reduced urinary incontinence in men at 3 months and at 1 year after radical prostatectomy more than placebo electrotherapy.

*See glossary.

Source of funding: Fund of Scientific

Research.

For correspondence: Dr $M$ Van Kampen, Department of Physiotherapy, Faculty of Education and Physiotherapy, University Hospital, KU Leuven, Belgium. Fax +3216346866

A modified version of this abstract also appears in

Evidence-Based Nursing.

Pelvic floor re-education (PFR) v placebo after radical prostatectomy

\begin{tabular}{lrlll} 
Outcomes & PFR & Placebo & RRR (95\% Cl) & NNT (CI) \\
Incontinence at 3 months & $10 \%$ & $44 \%$ & $77 \%(48$ to 91$)$ & 3 (2 to 6$)$ \\
\hline Incontinence at 1 year & $4 \%$ & $17 \%$ & $77 \%(11$ to 94$)$ & 8 (4 to 72$)$ \\
\hline
\end{tabular}

†Abbreviations defined in glossary; all numbers calculated from data in article.

\section{COMMENTARY}

A recent systematic review found unclear evidence of the benefit of conservative management of incontinence after prostatectomy. ${ }^{1}$ Close examination of the trials showed that only 1 was a genuine comparison of PFR with no treatment. ${ }^{2}$ The study by Van Kampen et al, which was included in the systematic review, compared PFR with placebo stimulation.

The methodological quality, sample size, and duration of follow up suggest that the results are meaningful and provide good evidence of the effect of PFR on incontinence. Clearly, spontaneous recovery also occurred, and some men (11\%) had a persistent leakage problem. The findings suggest that PFR should be offered to all men after prostatectomy until further evidence confirms which patients will benefit most. It is not clear whether urodynamics would identify those men most likely to benefit from PFR, but a trial of incontinent women referred for conservative management found no difference in outcome for those who had urodynamic diagnoses. ${ }^{3}$

PFR involves repeated voluntary contractions to rehabilitate striated muscle components of the continence mechanism affected by surgery. The authors provided only a limited description of PFR; but the 2 study groups were offered the same number of clinic visits and duration of treatment, and so the observed benefit of PFR is likely the result of training effects. The substantial commitment of men and healthcare resources for weekly clinic visits should be considered if the results are to be applied in practice. Future research should include a validated quality of life measure for urinary incontinence in men to determine what benefits, if any, men observe in their daily lives. Jean Hay-Smith, MSc University of Otago, Dunedin, New Zealand

1 Moore KN, Cody DJ, Glazener CM. Conservative management of post prostatectomy incontinence. Cochrane Review, latest version 22 Jul 1999. In: Cochrane Library. Oxford: Update Software.

2 Franke JJ, Gilbert WB, Grier J, et al. Early post-prostatectomy pelvic floor biofeedback. J Urol 2000;163:191-3.

3 Ramsay I, Hassan A, Hunter M, et al. A randomised controlled trial of urodynamic investigations prior to conservative treatment of urinary incontinence in the female [abstract]. Neurourol Urodyn 1994;13:455-6. 